\title{
Efficacy and safety of dose-dense chemotherapy in urothelial carcinoma
}

\author{
Chenjing Zhu ${ }^{1, *}$, Jiaming Liu ${ }^{2, *}$, Jing Zhang ${ }^{3, *}$, Qingfang Li ${ }^{1}$, Qisi Lian ${ }^{4}$, Jing $\mathbf{X u}^{3}$ and \\ Xuelei Ma ${ }^{1}$ \\ ${ }^{1}$ Cancer Center, State Key Laboratory of Biotherapy, West China Hospital, Sichuan University, Chengdu, Sichuan, China \\ ${ }^{2}$ Department of Urology, Institute of Urology, Laboratory of Reconstructive Urology, West China Hospital, Sichuan University, \\ Chengdu, Sichuan, China \\ ${ }^{3}$ West China School of Medicine, West China Hospital, Sichuan University, Chengdu, Sichuan, China \\ ${ }^{4}$ West China School of Stomatology, Sichuan University, Chengdu, Sichuan, China \\ *These authors contributed equally to this work
}

Correspondence to: Xuelei Ma, email: drmaxuelei@gmail.com

Keywords: dose-dense, urothelial carcinoma, meta-analysis

Received: August 08, $2016 \quad$ Accepted: March 22, 2017

Published: March 31, 2017

Copyright: Zhu et al. This is an open-access article distributed under the terms of the Creative Commons Attribution License 3.0 (CC BY 3.0), which permits unrestricted use, distribution, and reproduction in any medium, provided the original author and source are credited.

\section{ABSTRACT}

We conducted a meta-analysis to assess the efficacy and safety of dose-dense chemotherapy in the treatment of patients with urothelial carcinoma. A systematic search was conducted in PubMed, Medline, Embase, Web of Science and Cochrane Collaboration's Central register of controlled trials (CENTRAL) for relevant articles. Data was obtained from 10 trials with a total of 1093 patients. The pooled pathologic complete response (PCR) was $27.8 \%$ in the ten studies with a full cohort of 684 patients who received dose-dense methotrexate, vinblastine, adriamycin and cisplatin (dd-MVAC). In the controlled trials, although the difference was not significant, the PCR rate in the dd-MVAC group has a trend of increase (odds ratio (OR) 1.52; $95 \%$ confidence interval $(C I) 0.78-2.98, P=0.22$ ) compared with classic MVAC group. A significant improvement of overall survival (OS) (hazard ratio (HR) 0.77 , 95\% CI 0.61-0.97, $p=0.03$ ) was also observed. Hematologic toxicities were the most frequent grade $\geq 3$ toxicities including neutropenia/febrile neutropenia $(17.5 \%)$, anemia $(9.4 \%)$ and thrombocytopenia $(6.1 \%)$. Compared with the classic MVAC group, dd-MVAC was associated with significantly decreased risks of all-grade adverse events (AEs) such as anemia (OR 0.457, 95\% CI 0.249-0.840, $p=0.012$ ), febrile neutropenia (OR $0.39895 \%$ CI $0.233-0.681, p=0.001$ ), and neutropenia (OR $0.373,95 \% \mathrm{CI} 0.201-0.691, p=0.002)$. In conclusion, dose-dense chemotherapy was effective and tolerable in patients with urothelial carcinoma, which could be considered as a reasonable therapeutic option.

\section{INTRODUCTION}

Urothelial carcinoma (UC) is a significant health problem. In 2008, it led to an estimated 150,200 deaths worldwide [1]. Twenty-five percent of UCs were invasive $[2,3]$. According to the European Urology Association (EAU), radical cystectomy (RC) with bilateral pelvic lymphadenectomy was the gold standard treatment for patients with muscle-invasive tumors [4].

The classic MVAC regimen (methotrexate, vinblastine, doxorubicin and cisplatin) [5] was established as the most effective regimen (4-week-per-cycle) in the neoadjuvant chemotherapy setting [6], and the first recognized option for patients with locally advanced or metastatic UC [7]. In 1993, the classic MVAC regimen was modified into dose-dense MVAC (dd-MVAC) which was administered in cycles of 14 days. Dd-MVAC was shown to have fewer dose delays and a more favorable toxicity profile than classic MVAC group [8] in a randomized phase III trial, however in another study [9], similar pathological responses were observed between the two groups. 
To systematically review the safety and efficacy of dose-dense chemotherapy, we assessed the pathologic complete response (pCR), objective response rate (ORR), overall survival (OS) and adverse events (AEs) of dosedense chemotherapy, dd-MVAC in particular, in patients with UC. We also compared the efficacy and safety of ddMVAC with classic MVAC.

\section{RESULTS}

\section{Literature search}

The initial search yielded 849 unique articles after deletion of duplicates. After title and abstract screening, 555 were excluded as they were case reports, letters, review articles, or irrelevant to urothelial cancer, leaving 294 articles for full review. After assessing the full texts of these potentially relevant studies, 284 were excluded for the following reasons: 189 were researches on radiation therapy, 85 were completely not associated with dose-dense chemotherapy, 5 were about adjuvant therapy, 4 contained no relative outcomes, and 1 was with a too small sample size. Ultimately, 10 eligible articles [7, 9-17] involving a total of 1093 patients were included for analyses. No additional unpublished trials were added to the literature search results. A flow diagram of the trial selection process is shown in Figure 1.

\section{Study characteristics}

Results of the literature search identified 10 eligible papers. Among those papers, three [7, 9, 16] were controlled trials comparing dd-MVAC with classic MVAC, one [17] was another controlled trial comparing a dd-GC (gemcitabine $2500 \mathrm{mg} / \mathrm{m} 2$ and cisplatin $70 \mathrm{mg} / \mathrm{m} 2$, q 2 weeks) regimen with dd-MVAC which suggested that although not superior to dd-MVAC, dd-GC was better tolerated, and one [11] was AG-TC which was doxorubicin plus gemcitabine followed by paclitaxel plus carboplatin. The rest were single-arm trials exploring the safety and/or the activity of dd-MVAC regimen. Dd-MVAC chemotherapy consisted of methotrexate (MTX) $30 \mathrm{mg} / \mathrm{m} 2$, vinblastine (VBL) $3 \mathrm{mg} / \mathrm{m} 2$, adriamycin (ADM) $30 \mathrm{mg} / \mathrm{m} 2$ and cisplatin (CDDP) $70 \mathrm{mg} / \mathrm{m} 2$, administered in cycles of 14 days. Classic MVAC was a 4-week-per-cycle regimen which was also the combination of MTX $30 \mathrm{mg} / \mathrm{m} 2$, VBL $3 \mathrm{mg} / \mathrm{m} 2$, ADM $30 \mathrm{mg} / \mathrm{m} 2$ and CDDP $70 \mathrm{mg} / \mathrm{m} 2$. The majority of the patients were men. The age ranged from 32 to 83 years. The basic characteristics of the included studies are detailed in Table 1.

\section{Response and survival}

In the ten studies with a full cohort of 684 patients who received dd-MVAC, the pooled pCR was $27.8 \%$

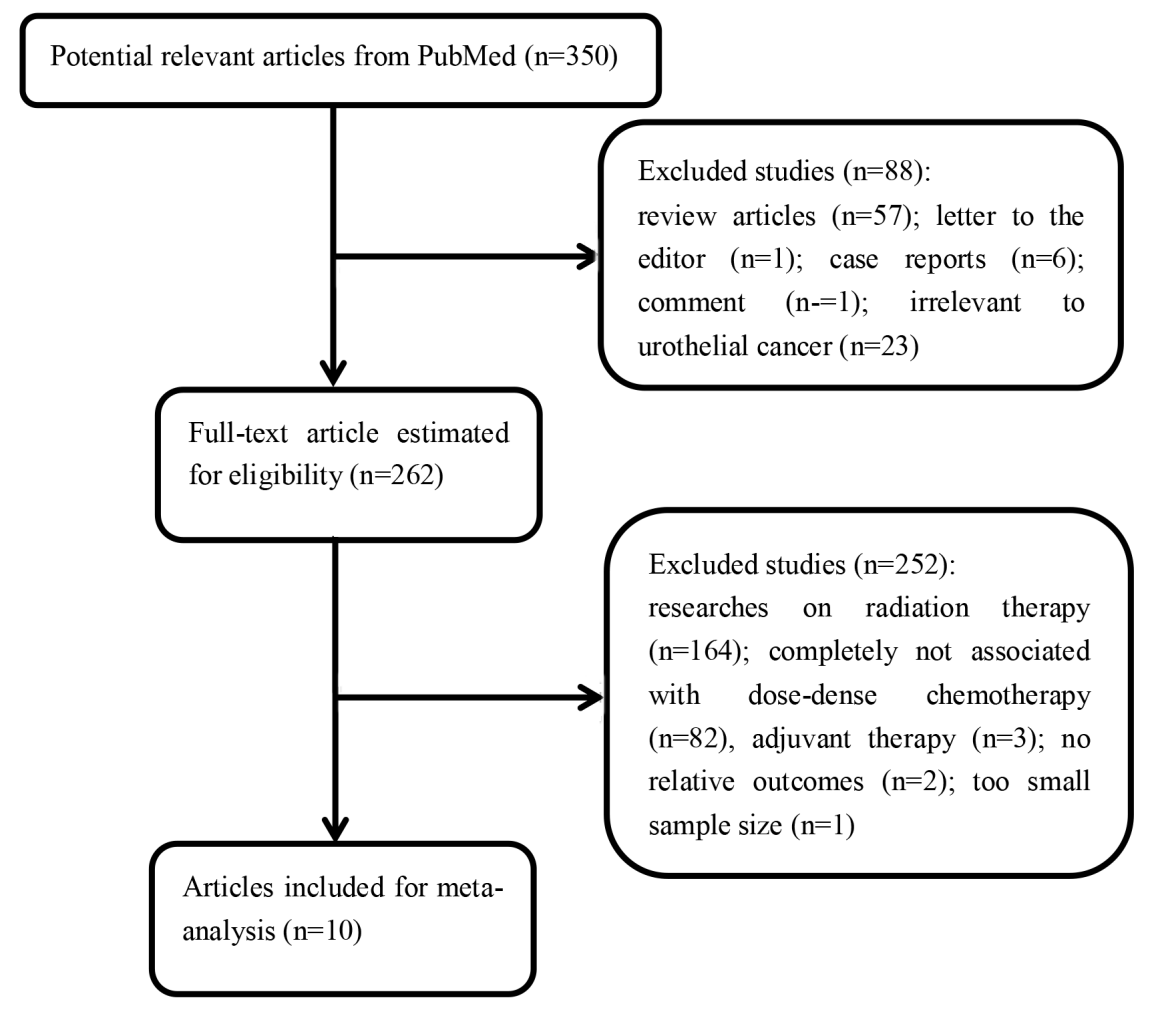

Figure 1: A flow diagram of the trial selection process. 
Table 1: Basic characteristics of the included studies

\begin{tabular}{|c|c|c|c|c|c|c|c|c|c|c|c|}
\hline Author & Year & Country & Tumor type & $\begin{array}{l}\text { Type of } \\
\text { study }\end{array}$ & $\begin{array}{c}\text { No. of } \\
\text { patients }\end{array}$ & $\begin{array}{c}\text { Sex (Male/ } \\
\text { Female) }\end{array}$ & Median age (range) (y) & Tumor stage & Chemotherapy regimens (mg/m2) & $\begin{array}{c}\text { No. of } \\
\text { planned cycles }\end{array}$ & No. of $\mathrm{pCR}$ (total) \\
\hline \multirow[t]{3}{*}{$\begin{array}{c}\text { van de Putte } \\
\text { EE }\end{array}$} & 2016 & Netherlands & $\begin{array}{l}\text { Muscle invasive } \\
\text { bladder cancer } \\
\text { (MIBC) }\end{array}$ & Retrospective & dd-MVAC: 80 & $60 / 20$ & mean (SD) 57 (8) & T1-4 N0-3 M0-1 & dd-MVAC (M 30, V 3, D 30, C 70 q 2 weeks) & 4 & $23(80)$ \\
\hline & & & & & MVAC: 35 & $26 / 9$ & $59(9)$ & & MVAC (M 30, V 3, D 30, C 70 q 4 weeks) & 4 & $7(35)$ \\
\hline & & & & & GC: 51 & $36 / 15$ & $63(8)$ & & $\mathrm{GC}(\mathrm{G} 1000, \mathrm{C} 70 \mathrm{q} 3$ weeks) & 4 & $16(51)$ \\
\hline \multirow[t]{2}{*}{ Bamias A } & 2013 & Greek & $\begin{array}{l}\text { Advanced urothelial } \\
\text { cancer (UC) }\end{array}$ & $\begin{array}{l}\text { Prospective, } \\
\text { Phase III }\end{array}$ & dd-MVAC: 66 & $53 / 10$ & $66(35-76)$ & $\mathrm{cT} 4 \mathrm{~b}$ N2 N3 & dd-MVAC (M 30, V 3, A 30, C 70 q 2 weeks) & $\geq 6$ & $5(45)$ \\
\hline & & & & & dd-GC: 64 & $55 / 8$ & $65(34-80)$ & & dd-GC (G 2500, C 70 q 2 weeks) & $\geq 6$ & $5(49)$ \\
\hline \multirow[t]{2}{*}{ Pouessel D } & 2016 & France & $\begin{array}{l}\text { Advanced urothelial } \\
\text { bladder cancer }\end{array}$ & Retrospective & $\begin{array}{c}\text { dd-MVAC: } \\
189\end{array}$ & $160 / 29$ & $63(57-67)$ & T2-4a N1-3 M0 & dd-MVAC (M 30, V 3, D 30, C 70 q 2 weeks) & $4-6$ & $58(166)$ \\
\hline & & & & & MVAC: 52 & $43 / 9$ & $58(55-66)$ & & MVAC (M 30, V 3, D 30, C 70 q 4 weeks) & $3-4$ & $17(45)$ \\
\hline \multirow[t]{2}{*}{ Sternberg $\mathrm{CN}$} & 2005 & Multicenter & $\begin{array}{l}\text { Advanced urothelial } \\
\text { cancer (UC) }\end{array}$ & phase III & $\begin{array}{l}\text { dd-MVAC: } \\
134\end{array}$ & $105 / 29$ & $61(36-76)$ & $\mathrm{NA}$ & dd-MVAC (M 30, V 3, D 30, C 70 q 2 weeks) & 6 & $28(134)$ \\
\hline & & & & & MVAC: 129 & $107 / 22$ & $62(32-81)$ & & MVAC (M 30, V 3, D 30, C 70 q 4 weeks) & 4 & $12(129)$ \\
\hline Choueiri TK & 2014 & Multicenter & $\begin{array}{l}\text { Muscle invasive } \\
\text { urothelial cancer } \\
\text { (MIUC) }\end{array}$ & $\begin{array}{c}\text { Prospective, } \\
\text { phase II }\end{array}$ & 39 & $28 / 11$ & $\mathrm{NA}$ & cT2-cT4 N0-1 M0 & dd-MVAC (M 30, V 3, D 30, C 70 q 2 weeks) & 4 & $10(36)$ \\
\hline Galsky MD & 2007 & USA & $\begin{array}{l}\text { Advanced Urothelial } \\
\text { Carcinoma }\end{array}$ & Phase II & 25 & $\mathrm{NA}$ & $67(43-79)$ & $\mathrm{NA}$ & AG-TC* & 5 & $5(25)$ \\
\hline Plimack ER & 2014 & Multicenter & $\begin{array}{l}\text { Muscle invasive } \\
\text { bladder cancer } \\
\text { (MIBC) }\end{array}$ & $\begin{array}{l}\text { Prospective, } \\
\text { phase II }\end{array}$ & 44 & $30 / 14$ & $64(44-83)$ & cT2-T4a N0-N1 M0 & dd-MVAC (M 30, V 3, D 30, C 70) & 3 & $15(40)$ \\
\hline Blick C & 2012 & UK & $\begin{array}{l}\text { Muscle invasive } \\
\text { bladder cancer } \\
\text { (MIBC) }\end{array}$ & Retrospective & 80 & $64 / 16$ & $60(41-74)$ & T2-4a N0-2 M0 & dd-MVAC (M 30, V 3, D 30, C 70 q 2 weeks) & 3 or 4 & $26(60)$ \\
\hline $\begin{array}{l}\text { McConkey } \\
\text { DJ }\end{array}$ & 2015 & USA & $\begin{array}{l}\text { Muscle invasive } \\
\text { urothelial cancer } \\
\text { (MIUC) }\end{array}$ & Phase II & 60 & 40/20 & $64(42-79.6)$ & T1-4a N0 M0 & dd-MVAC (M 30, V 3, D 30, C 70 q 2 weeks) & 4 & $23(60)$ \\
\hline Edeline $\mathrm{J}$ & 2012 & France & $\begin{array}{l}\text { Advanced bladder } \\
\text { cancer }\end{array}$ & Retrospective & 45 & $36 / 9$ & $58(36-79)$ & $\mathrm{NA}$ & dd-MVAC (M 30, V 3, D 30, C 70 q 2 weeks) & $\geq 1$ & $4(38)$ \\
\hline
\end{tabular}

NA: not availab

(95\% confidence interval (CI) $0.217-0.349, p<0.001$ ) (Figure 2). The rate of pCR was presented in three controlled studies that compared dd-MVAC with classic MVAC. No significant difference was detected in the odds of achieving a pCR with dd-MVAC versus classic MVAC (odds ratio 1.52, 95\% CI 0.78-2.98, $P=0.22, I^{2}=55 \%$, random-effects model) (Figure 3A). In addition, there was no significant improvement in terms of ORR between the dd-MVAC group compared with classic MVAC group, with an odds ratio of 0.98 ( $95 \%$ CI $0.48-1.99, p=0.96$, $\mathrm{I}^{2}=60 \%$, random-effects model) (Figure 3B).
As for long-term survival, a significantly improved OS was noted with dd-MVAC treatment when compared with classic MVAC treatment (hazard ratios (HR) 0.77, $95 \%$ CI $0.61-0.97, p=0.03, I^{2}=0 \%$, fixed-effects model) (Figure 3C).

\section{Toxicity}

We analyzed the rates of all-grade and grade 3 or more AEs in the ten included studies to evaluate the safety of dose-dense chemotherapy. In all-grade AEs, the highest

\begin{tabular}{lcccrr} 
Author & \multicolumn{5}{c}{ Statistics for each study } \\
& $\begin{array}{c}\text { Event } \\
\text { rate }\end{array}$ & $\begin{array}{c}\text { Lower } \\
\text { limit }\end{array}$ & $\begin{array}{c}\text { Upper } \\
\text { limit }\end{array}$ & Z-Value & p-Value \\
van de Putte EE & 0.288 & 0.199 & 0.396 & -3.674 & 0.000 \\
Bamias A & 0.111 & 0.047 & 0.241 & -4.384 & 0.000 \\
Pouessel D & 0.349 & 0.281 & 0.425 & -3.819 & 0.000 \\
Sternberg CN & 0.209 & 0.148 & 0.286 & -6.265 & 0.000 \\
Choueiri TK & 0.278 & 0.156 & 0.444 & -2.568 & 0.010 \\
Galsky MD & 0.200 & 0.086 & 0.400 & -2.773 & 0.006 \\
Plimack ER & 0.375 & 0.240 & 0.532 & -1.564 & 0.118 \\
Blick C & 0.433 & 0.315 & 0.560 & -1.030 & 0.303 \\
McConkey DJ & 0.383 & 0.270 & 0.511 & -1.790 & 0.073 \\
Edeline J & 0.105 & 0.040 & 0.249 & -4.049 & 0.000 \\
& 0.278 & 0.217 & 0.349 & -5.670 & 0.000
\end{tabular}

Event rate and $95 \% \mathrm{Cl}$
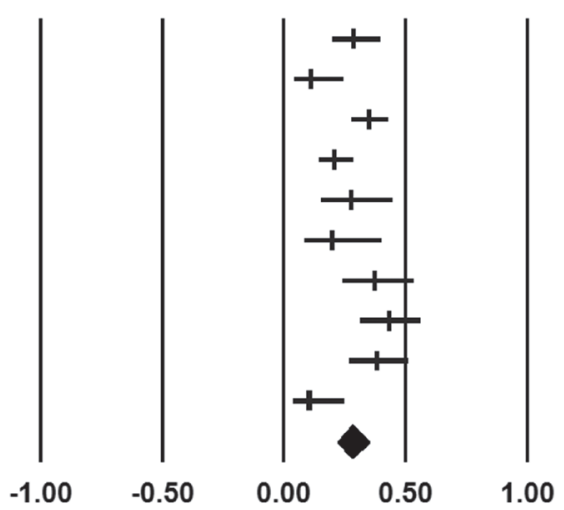

Favours [MVAC] Favours [dd-MVAC]

Meta Analysis

Figure 2: The pooled pathologic complete response (pCR) in the ten included studies. 
risk was found for fatigue $(60.7 \%, 95 \%$ CI $0.505-0.701$, $I^{2}=49.967 \%$, fixed-effects model). Thrombocytopenia was also common with the event rate of $43.2 \%$ (95\% CI $0.308-0.566, I^{2}=67.955 \%$ ) using a random-effects model (Table 2, Figure 4).

The grade $\geq 3$ toxicities were predominantly hematologic. Neutropenia/febrile neutropenia (17.5\%, 95\% CI $0.096-0.296, I^{2}=84.806 \%$, random-effects model), anemia (9.4\%, 95\% CI 0.035-0.228, $I^{2}=87.575 \%$, random-effects model), fatigue $(7.7 \%, 95 \%$ CI $0.049-0.118$, $I^{2}=4.430 \%$, fixed-effects model), sepsis (7.4\%, 95\% CI $0.038-0.142, I^{2}=42.331 \%$, fixed-effects model), and thrombocytopenia $\left(6.1 \%, 95 \%\right.$ CI $0.020-0.175, I^{2}=84.951 \%$, random-effects model) were the most frequent high-grade treatment-related adverse events (Table 2, Figure 5).

We further calculated the OR of all-grade adverse events between the dose-dense chemotherapy and classic chemotherapy groups. No statistical heterogeneity was observed in each adverse event except for thrombocytopenia, which was analyzed with a randomeffects model. The results showed that compared with the classic MVAC group, dd-MVAC was associated with decreased risks of anemia (OR $0.457,95 \%$ CI $0.249-0.840$, $p=0.012, \mathrm{I}^{2}=0.000$, fixed-effects model), febrile neutropenia (OR $0.39895 \%$ CI $0.233-0.681, p=0.001$, $\mathrm{I}^{2}=29.370 \%$, fixed-effects model), and neutropenia (OR 0.373, 95\% CI 0.201-0.691, $p=0.002, \mathrm{I}^{2}=0.000$, fixed-effects model). Increased risks of kidney injury (OR 1.025, 95\% CI 0.528-1.987, $p=0.943, \mathrm{I}^{2}=0.000$, fixed-effects model) and neuropathy (OR 2.747, $95 \%$ CI $0.323-23.369, p=0.355, \mathrm{I}^{2}=0.000$, fixed-effects model) (Table 3, Figure 6) were found for dd-MVAC, but there were no significant differences.

\section{Risk of bias and quality assessment}

The risk of bias and quality assessments of the included studies are outlined in Figure 7A, 7B. The Jadad score of two controlled trials [7, 16] were 3 and one [9] got a score of 2. Overall, the quality of the included studies was satisfactory.

\section{DISCUSSION}

To the best of our knowledge, this is the first metaanalysis that assesses the tolerability and activity of dose-

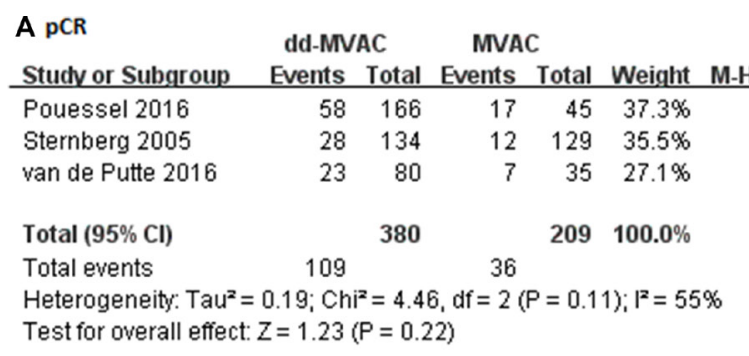

Odds Ratio Odds Ratio

$0.88[0.45,1.75]$

$2.58[1.25,5.32]$

$1.61[0.62,4.21]$

$1.52[0.78,2.98]$

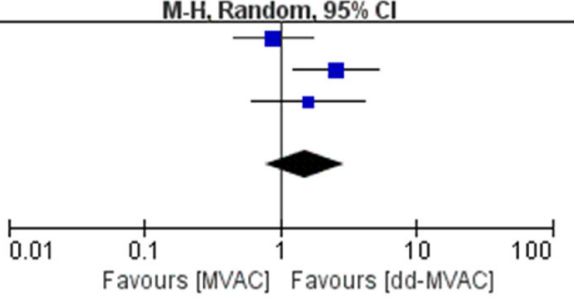

B ORR

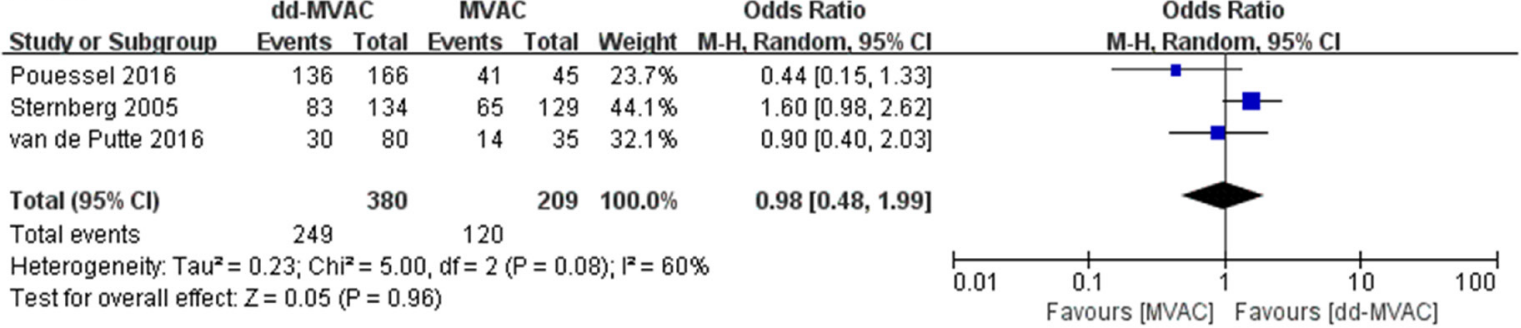

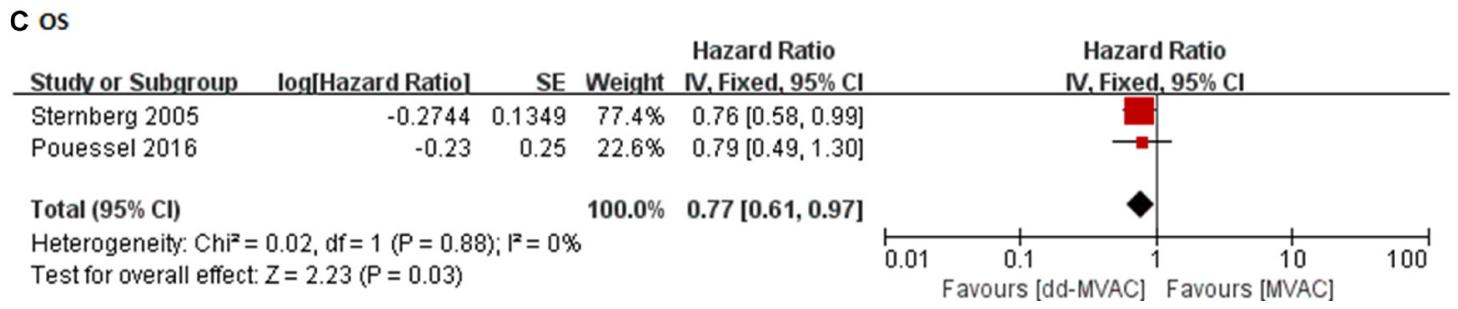

Figure 3: (A) The odds ratios of pathologic complete response (pCR) in the controlled trials comparing dd-MVAC and classic MVAC; (B) The odds ratios of objective response rate (ORR) in the controlled trials comparing dd-MVAC and classic MVAC; (C) Forest plots of the pooled hazard ratios (HRs) for OS. 
Table 2: The rate of all-grade and grade $\geq 3$ adverse events (AEs) for dose-dense MVAC

\begin{tabular}{llcc}
\hline $\begin{array}{c}\text { All-grade adverse } \\
\text { events }\end{array}$ & Model & Event rate with 95\% CI & $\mathbf{I}^{\mathbf{2}}$ \\
\hline Fatigue & Fixed model & $0.607(0.505-0.701)$ & 49.967 \\
Febrile neutropenia & Fixed model & $0.084(0.058-0.120)$ & 0.000 \\
Neuropathy & Fixed model & $0.055(0.032-0.095)$ & 0.000 \\
Kidney injury & Random model & $0.091(0.033-0.229)$ & 84.160 \\
Thrombocytopenia & Random model & $0.432(0.308-0.566)$ & 67.955 \\
\hline Grade $\geq \mathbf{3}$ adverse & Mvedel & Event rate with 95\% CI & $\mathbf{I}^{\mathbf{2}}$ \\
\hline Dehydration & Fixed model & $0.051(0.019-0.128)$ & 0.000 \\
Fatigue & Fixed model & $0.077(0.049-0.118)$ & 4.430 \\
Hyponatremia & Fixed model & $0.019(0.005-0.074)$ & 0.000 \\
Kidney injury & Fixed model & $0.025(0.012-0.052)$ & 9.112 \\
Mucositis & Fixed model & $0.029(0.009-0.087)$ & 0.000 \\
Nausea/vomiting & Fixed model & $0.046(0.022-0.094)$ & 0.000 \\
Neuropathy & Fixed model & $0.011(0.002-0.052)$ & 42.331 \\
Sepsis & Fixed model & $0.074(0.038-0.142)$ & 11.398 \\
Stomatitis & Fixed model & $0.038(0.012-0.112)$ & 0.000 \\
Thrombosis & Fixed model & $0.038(0.016-0.088)$ & 87.575 \\
Anemia & Random model & $0.094(0.035-0.228)$ & 84.806 \\
Neutropenia/febrile & Random model & $0.175(0.096-0.296)$ & 84.951 \\
neutropenia & Random model & $0.061(0.020-0.175)$ & \\
Thrombocytopenia & & & \\
\hline
\end{tabular}

Table 3: All-grade adverse events of dd-MVAC versus MVAC

\begin{tabular}{cccc}
\hline All-grade adverse events & Odds Ratio with 95\% CI & Model & $\mathbf{I}^{\mathbf{2}}$ \\
\hline Anemia & $0.457(0.249-0.840)$ & Fixed model & 0.000 \\
Febrile neutropenia & $0.398(0.233-0.681)$ & Fixed model & 29.370 \\
Kidney injury & $1.025(0.528-1.987)$ & Fixed model & 0.000 \\
Neuropathy & $2.747(0.323-23.369)$ & Fixed model & 0.000 \\
Neutropenia & $0.373(0.201-0.691)$ & Fixed model & 0.000 \\
Thrombocytopenia & $0.888(0.307-2.562)$ & Random model & 76.634 \\
\hline
\end{tabular}

dense chemotherapy in patients with urothelial carcinoma. Dose-dense MVAC led to a significant increase in longterm survival and a decrease in all-grade adverse events. The pCR rate in the dose-dense group had a trend of increase compared with the classic chemotherapy group, although the difference was not statistically significant.

The degree of pathologic response is correlated with survival after UC surgery [18]. A meta-analysis demonstrated that patients with UC who achieved pCR after neoadjuvant chemotherapy had better OS than do patients without pCR. In breast cancer settings, the relationship between pCR and OS has been obscure, sometimes significantly associated $[19,20]$, but sometimes not $[21,22]$. In our study, we assumed that the pCR rate and OS tended to increase in the dose-dense group, and no statistical difference might largely rely on the limited sample size.

The improved overall survival represented the advantage of long-term survival in dd-MVAC group, which was presumed to arise from the elimination of micrometastatic disease, instead of from improved local disease control [13]. In addition, better median progression-free survival was suggested by one study [16] with dd-MVAC (9.5 months) vs. classic MVAC (8.1 months) (HR $=0.73,95 \%$ CI $0.56-0.95, P=0.017$ ).

Concomitantly, the toxicity data demonstrated that dd-MVAC was associated with a better tolerability than classic MVAC. The fewer adverse events were most probably due to bone marrow support with the routine addition of G-CSF [7, 16]. Toxicities may cause a delay in cystectomy or even deaths. All-grade AEs such as fatigue and thrombocytopenia were the most common, and it is suggested that surgeons still need to pay particular attention to grade $\geq 3$ hematologic toxicities including neutrophil, erythrocyte and platelet toxicities.

The introduction of dose-dense combination chemotherapy provides advantages over standard chemotherapy. First, dose-dense chemotherapy has the 
potential to increase response rates as well as reduce the risk of progression and death $[23,24]$. Second, a large proportion of patients achieved the planned number of cycles without serious life-threatening toxicity with the administration of G-CSF.

What's more, it is important to identify the optimal cycle of dd-MVAC. The number of cycles was variable in the included publications, but most studies adopted 3-5 cycles which displayed less toxicity and fewer dose delays.

There are several limitations in our study. First, because this dose-dense chemotherapy regimen is brought forward only recently which is rather new, there are few clinical trials about it. Second, the heterogeneity in our analysis could arise from the heterogeneous study population with pre-treated disease and the small sample size. Nevertheless, we used the random-effects model to reduce heterogeneity and also performed risk of bias and quality assessments and the Jadad score analyses to assess the quality of the included studies which turned out to be satisfactory.

Our systematic analyses of prospective and retrospective experiences with dd-MVAC suggested similar efficacy combined with better tolerability. We consider that the use of dose-dense chemotherapy regimen could be a trend in future treatment of patients with urothelial carcinoma. Further randomized trials comparing the two regimens are needed.

\section{MATERIALS AND METHODS}

\section{Literature search}

We carried out a systematic literature search up to Nov 21, 2016 in PubMed, Medline, Embase, Web of Science and Cochrane Collaboration's Central register of controlled trials (CENTRAL), using the following search keywords: (dose dense OR dose-dense OR high-dose intensity OR accelerated OR dose-intensified OR dose-intensive) and (urothelial OR bladder) and (cancer OR carcinoma). There was no limit on the language of publications. We also carried out further searches for relevant unpublished trials in the clinical trial registry (http://www.clinicaltrials.gov).

\section{Study selection criteria}

The inclusion criteria for the current analysis were that studies (i) included patients diagnosed with urothelial cancer; (ii) evaluated dose-dense chemotherapy; (iii)

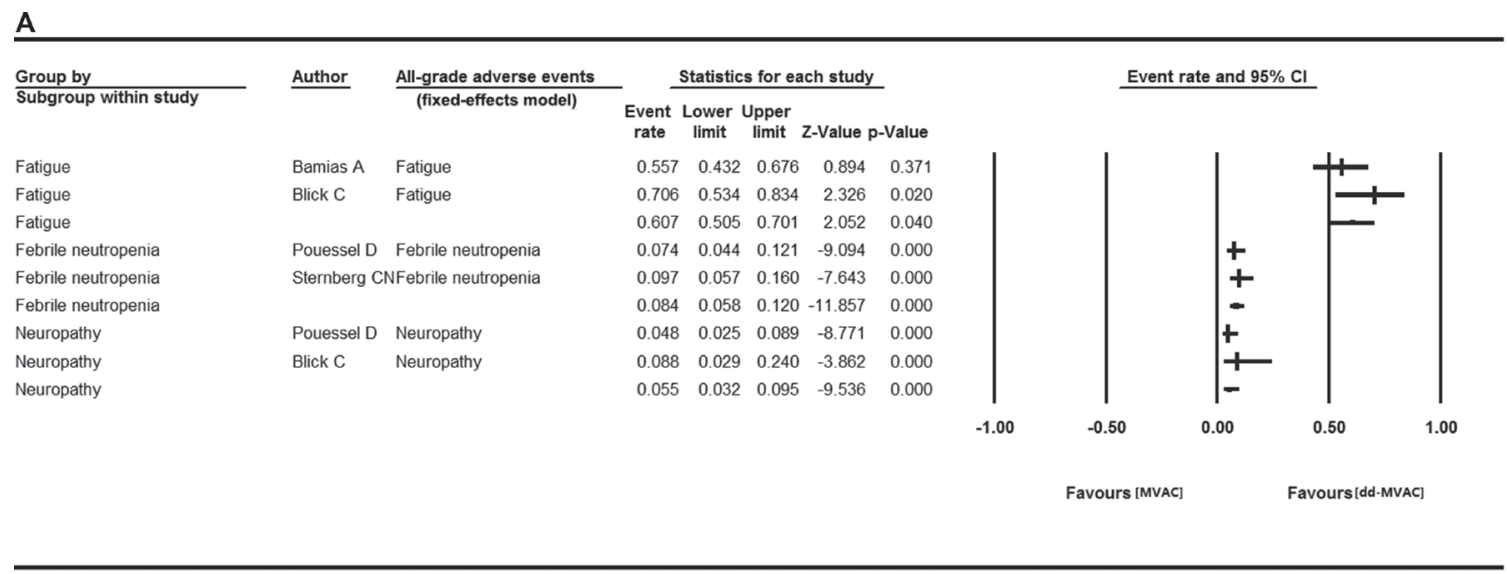

Meta Analysis

B

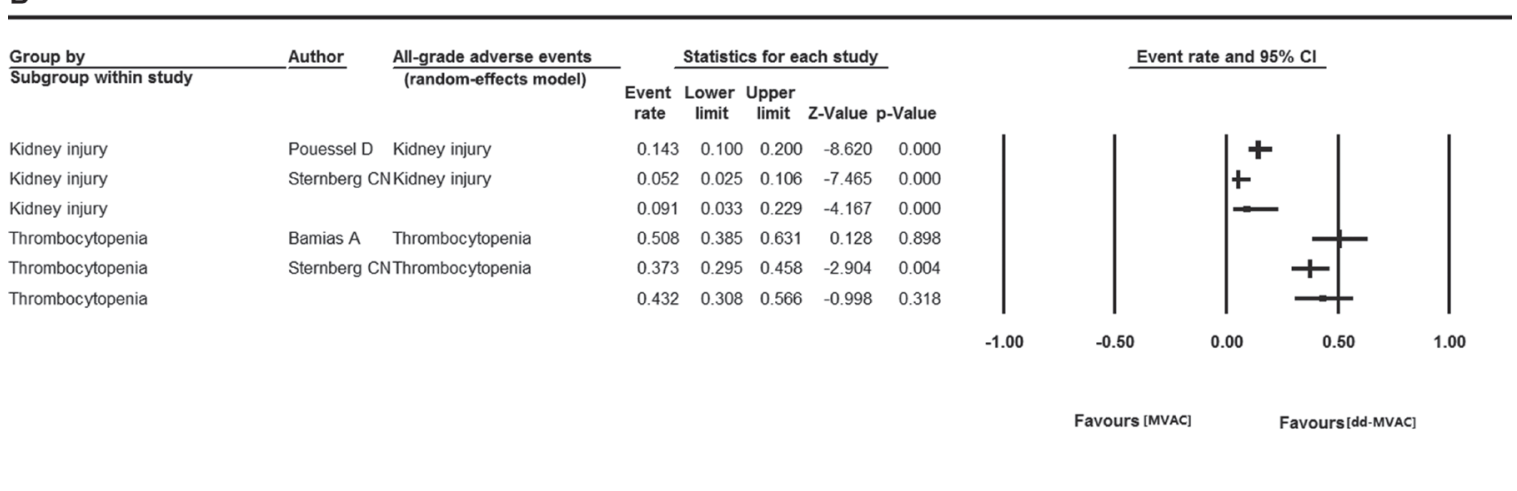

Meta Analysis

Figure 4: All-grade AEs in the ten included studies (A) fixed-effects model; (B) random-effects model. 
reported survival outcomes of patients ( $\mathrm{pCR}$ or OS or PFS or ORR); and (iiii) evaluated the toxicities.

Studies were excluded if (i) they were review articles, letters, comments, or case reports; (ii) they evaluated radiotherapy, or high-dose rather than dose- dense chemotherapy; (iii) the sample size was less than 20 patients. The study selection process was performed according to PRISMA flow diagrams. Two reviewers selected studies independently. Any disagreements were resolved through discussion with another author.

\begin{tabular}{|c|c|c|c|c|c|c|c|}
\hline \multirow{2}{*}{$\begin{array}{l}\text { Group by } \\
\text { Subgroup within study }\end{array}$} & \multirow[t]{2}{*}{ Author } & \multicolumn{2}{|c|}{ Grade $\geq 3$ adverse events } & \multicolumn{4}{|c|}{ Statistics for each study } \\
\hline & & $\overline{\text { (Fixed-effects model) }}$ & $\begin{array}{c}\text { Event } \\
\text { rate }\end{array}$ & $\begin{array}{c}\text { Lower } \\
\text { limit }\end{array}$ & $\begin{array}{c}\text { Upper } \\
\text { limit }\end{array}$ & z-Value & p-Value \\
\hline Dehydration & Plimack ER & Dehydration & 0.023 & 0.003 & 0.144 & -3.718 & 0.000 \\
\hline Dehydration & Edeline $\mathrm{J}$ & Dehydration & 0.067 & 0.022 & 0.187 & -4.416 & 0.000 \\
\hline Dehydration & & & 0.051 & 0.019 & 0.128 & -5.693 & 0.000 \\
\hline Fatigue & van de Putte EE & Fatigue & 0.025 & 0.006 & 0.096 & -5.097 & 0.000 \\
\hline Fatigue & Bamias A & Fatigue & 0.082 & 0.035 & 0.182 & -5.176 & 0.000 \\
\hline Fatigue & Plimack ER & Fatigue & 0.068 & 0.022 & 0.191 & -4.372 & 0.000 \\
\hline Fatigue & Blick C & Fatigue & 0.059 & 0.015 & 0.207 & -3.804 & 0.000 \\
\hline Fatigue & McConkey DJ & Fatigue & 0.117 & 0.057 & 0.225 & -5.034 & 0.000 \\
\hline Fatigue & & & 0.077 & 0.049 & 0.118 & -10.369 & 0.000 \\
\hline Hyponatremia & Plimack ER & Hyponatremia & 0.023 & 0.003 & 0.144 & -3.718 & 0.000 \\
\hline Hyponatremia & McConkey DJ & Hyponatremia & 0.017 & 0.002 & 0.109 & -4.043 & 0.000 \\
\hline Hyponatremia & & & 0.019 & 0.005 & 0.074 & -5.489 & 0.000 \\
\hline Kidney injury & van de Putte EE & Kidney injury & 0.038 & 0.012 & 0.111 & -5.491 & 0.000 \\
\hline Kidney injury & Bamias A & Kidney injury & 0.033 & 0.008 & 0.122 & -4.707 & 0.000 \\
\hline Kidney injury & Pouessel D & Kidney injury & 0.011 & 0.003 & 0.041 & -6.384 & 0.000 \\
\hline Kidney injury & & & 0.025 & 0.012 & 0.052 & -9.532 & 0.000 \\
\hline Mucositis & Plimack ER & Mucositis & 0.023 & 0.003 & 0.144 & -3.718 & 0.000 \\
\hline Mucositis & McConkey DJ & Mucositis & 0.033 & 0.008 & 0.124 & -4.682 & 0.000 \\
\hline Mucositis & & & 0.029 & 0.009 & 0.087 & -5.970 & 0.000 \\
\hline Nausea/vomiting & Bamias A & Nausea/vomiting & 0.033 & 0.008 & 0.122 & -4.707 & 0.000 \\
\hline Nausea/vomiting & Blick C & Nausea/vomiting & 0.059 & 0.015 & 0.207 & -3.804 & 0.000 \\
\hline Nausea/vomiting & McConkey DJ & Nausea/vomiting & 0.050 & 0.016 & 0.144 & -4.971 & 0.000 \\
\hline Nausea/vomiting & & & 0.046 & 0.022 & 0.094 & -7.807 & 0.000 \\
\hline Neuropathy & van de Putte EE & Neuropathy & 0.013 & 0.002 & 0.084 & -4.329 & 0.000 \\
\hline Neuropathy & Bamias A & Neuropathy & 0.008 & 0.001 & 0.116 & -3.389 & 0.001 \\
\hline Neuropathy & & & 0.011 & 0.002 & 0.052 & -5.492 & 0.000 \\
\hline Sepsis & van de Putte EE & Sepsis & 0.089 & 0.043 & 0.174 & -5.887 & 0.000 \\
\hline Sepsis & Plimack ER & Sepsis & 0.023 & 0.003 & 0.144 & -3.718 & 0.000 \\
\hline Sepsis & & & 0.074 & 0.038 & 0.142 & -6.837 & 0.000 \\
\hline Stomatitis & Bamias A & Stomatitis & 0.016 & 0.002 & 0.107 & -4.061 & 0.000 \\
\hline Stomatitis & Blick C & Stomatitis & 0.059 & 0.015 & 0.207 & -3.804 & 0.000 \\
\hline Stomatitis & & & 0.038 & 0.012 & 0.112 & -5.462 & 0.000 \\
\hline Thrombosis & van de Putte EE & Thrombosis & 0.025 & 0.006 & 0.096 & -5.097 & 0.000 \\
\hline Thrombosis & McConkey DJ & Thrombosis & 0.050 & 0.016 & 0.144 & -4.971 & 0.000 \\
\hline Thrombosis & & & 0.038 & 0.016 & 0.088 & -7.079 & 0.000 \\
\hline
\end{tabular}

hrombosis 


\section{Data extraction}

We extracted the first author, year of publication, tumor type, study phase, sample size, chemotherapy regimens, the number of cycles of chemotherapy, patient characteristics (number of patients, sex, median age, and tumor stage). The number of patients achieving $\mathrm{pCR}$ and ORR, HRs for OS, and the number of chemotherapyinduced adverse events were also extracted from the papers.

\section{Statistical analysis}

The primary clinical endpoint used for the study was $\mathrm{pCR}$, defined as the absence of histological evidence of invasive tumor cells (pTON0M0 stage) [25]. The secondary clinical endpoints included (i) ORR, which was the summation of partial and complete response rates [26], (ii) OS, defined as the time from diagnosis of primary tumor to death, which can be from any cause [27], or the time to last contact; (iii) adverse events, which were graded according to the National Cancer Institute (Washington DC, USA) Common Toxicity Criteria.

For dichotomous outcomes, we calculated the odds ratio (OR) and 95\% confidence intervals (CIs). For timeto-event data, we pooled the HR to compare the risk of death between the treatment group and the control group, using the generic inverse variance facility of RevMan [28]. A 2-tailed $p$ value of less than 0.05 was considered as statistically significant. Statistical heterogeneity was defined as $\mathrm{I}^{2}>50 \%$ and $P \leq 0.1$. If the heterogeneity existed, we used the random-effects model. All analyses were done with Comprehensive Meta-Analysis (CMA) program 2 (Biostat, Englewood, NJ) and Review manager 5.3 (Copenhagen, Sweden).

\section{Risk of bias and quality assessment}

The assessment of risk of bias and the quality of the included studies was measured using Review Manager 5.3 (Copenhagen, Sweden). We applied the assessment

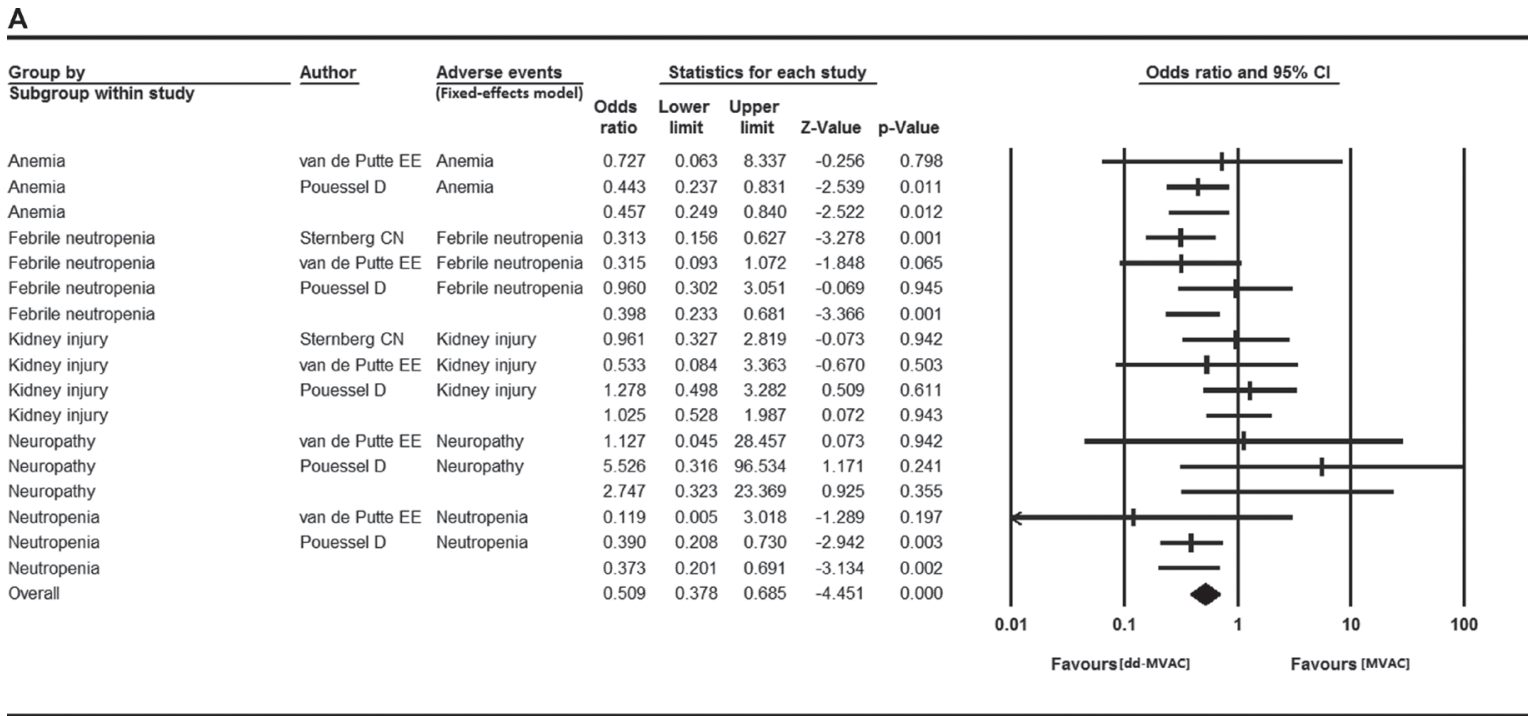

Meta Analysis

B

\begin{tabular}{|c|c|c|c|c|c|c|c|}
\hline \multirow{2}{*}{$\begin{array}{l}\text { Group by } \\
\text { Subgroup within study }\end{array}$} & \multirow[t]{2}{*}{ Author } & \multirow{2}{*}{$\frac{\text { Grade } \geq 3 \text { adverse events }}{\text { (Random-effects model) }}$} & \multicolumn{5}{|c|}{ Statistics for each study } \\
\hline & & & $\begin{array}{l}\text { Odds } \\
\text { ratio }\end{array}$ & $\begin{array}{l}\text { Lower } \\
\text { limit }\end{array}$ & $\begin{array}{l}\text { Upper } \\
\text { limit }\end{array}$ & Z-Value $p$ & -Value \\
\hline Thrombocytopenia & Sternberg CN & Thrombocytopenia & 1.480 & 0.882 & 2.484 & 1.484 & 0.138 \\
\hline Thrombocytopenia & van de Putte EE & E Thrombocytopenia & 1.903 & 0.089 & 40.828 & 0.411 & 0.681 \\
\hline Thrombocytopenia & Pouessel D & Thrombocytopenia & 0.435 & 0.227 & 0.833 & -2.512 & 0.012 \\
\hline Thrombocytopenia & & & 0.888 & 0.307 & 2.562 & -0.220 & 0.826 \\
\hline
\end{tabular}
Odds ratio and $95 \% \mathrm{Cl}$

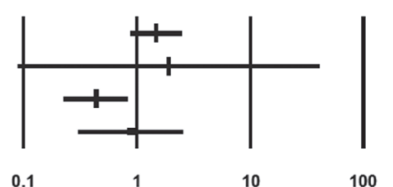

Favours [dd-MVAC] $\quad$ Favours [MVAC]

Meta Analysis

Figure 6: The odds ratios of adverse events (AEs) in the controlled trials comparing dd-MVAC and classic MVAC. (A) fixed-effects model; (B) random-effects model. 
tool QUADAS-2, which consisted of four key domains: patient selection, index test, reference standard and flow and timing. Risk of bias was rated as high/low/unclear. Two authors independently applied the risk of bias tool and differences were resolved by discussion with a third author.
We also utilized the Jadad scale to assess the qualities of the randomized controlled trials included in our study [29]. A score lower than 2 indicated that the clinical trial was of low quality while a score more than 3 indicated a high-quality design [30]. Two authors
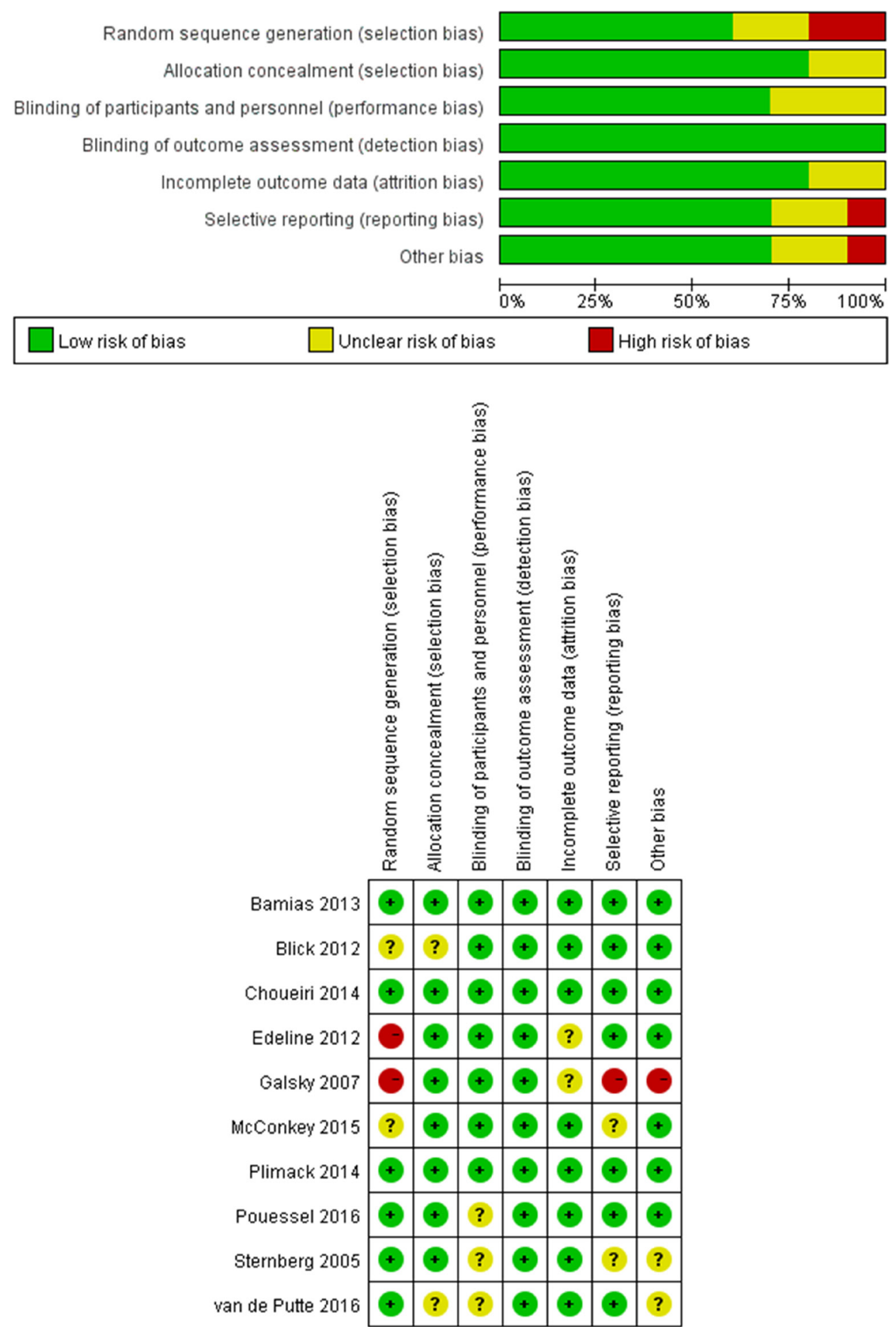

Figure 7: Risk of bias and quality assessment. (A) Risk of bias graph: review authors' judgments about each risk of bias item presented as percentages across all included studies; (B) Risk of bias summary: review authors' judgments about each risk of bias item for each included study. 
independently calculated the scores and differences were resolved by discussion with a third author.

\section{Authors' contributions}

Chenjing Zhu wrote the article, Xuelei Ma provided the idea, Qingfang Li and Qisi Lian collected the data, Jing $\mathrm{Xu}$ modified the article. All authors reviewed the manuscript.

\section{ACKNOWLEDGMENTS}

None.

\section{CONFLICTS OF INTEREST}

None.

\section{FUNDING}

Grant No. 2014K158 from the Administration of Traditional Chinese Medicine of Sichuan, Grant No. 2017SZ0048 from Science and Technology Administration, Sichuan Province, Grant No. 2014SZ0031 from Science and Technology Administration, Sichuan Province, Grant No. 16PJ298 from Health and Family Planning Commission of Sichuan Province. Grant No.2015-RK00-00233-ZF from Science and Technology Administration, Chengdu.Grant No. 2014K158 from the Administration of Traditional Chinese Medicine of Sichuan, Grant No. 2017SZ0048 from Science and Technology Administration, Sichuan Province, Grant No. 2014SZ0031 from Science and Technology Administration, Sichuan Province, Grant No. 16PJ298 from Health and Family Planning Commission of Sichuan Province. Grant No.2015-RK00-00233-ZF from Science and Technology Administration, Chengdu.Grant No. 2014K158 from the Administration of Traditional Chinese Medicine of Sichuan, Grant No. 2017SZ0048 from Science and Technology Administration, Sichuan Province, Grant No. 2014SZ0031 from Science and Technology Administration, Sichuan Province, Grant No. 16PJ298 from Health and Family Planning Commission of Sichuan Province. Grant No.2015-RK00-00233-ZF from Science and Technology Administration, Chengdu.

\section{REFERENCES}

1. Jemal A, Bray F, Center MM, Ferlay J, Ward E, Forman D. Global cancer statistics. CA Cancer J Clin. 2011; 61:69-90.

2. Ikeda M, Matsumoto K, Nishi M, Tabata K, Fujita T, Ishiyama H, Hayakawa K, Iwamura M. Comparison of radical cystectomy and chemoradiotherapy in patients with locally advanced bladder cancer. Asian Pac J Cancer Prev. 2014; 15:6519-24.

3. Stein JP, Lieskovsky G, Cote R, Groshen S, Feng AC, Boyd S, Skinner E, Bochner B, Thangathurai D, Mikhail M,
Raghavan D, Skinner DG. Radical cystectomy in the treatment of invasive bladder cancer: long-term results in 1,054 patients. J Clin Oncol. 2001; 19:666-75.

4. Witjes JA, Compérat E, Cowan NC, De Santis M, Gakis G, Lebret T, Ribal MJ, Van der Heijden AG, Sherif A. EAU guidelines on muscle-invasive and metastatic bladder cancer: summary of the 2013 guidelines. Eur Urol. 2014; 65:778-92.

5. von der Maase H, Sengelov L, Roberts JT, Ricci S, Dogliotti L, Oliver T, Moore MJ, Zimmermann A, Arning M. Long-term survival results of a randomized trial comparing gemcitabine plus cisplatin, with methotrexate, vinblastine, doxorubicin, plus cisplatin in patients with bladder cancer. J Clin Oncol. 2005; 23:4602-8.

6. Sternberg $\mathrm{CN}$, de Mulder $\mathrm{PH}$, van Oosterom AT, Fossa SD, Giannarelli D, Soedirman JR. Escalated M-VAC chemotherapy and recombinant human granulocytemacrophage colony stimulating factor (rhGM-CSF) in patients with advanced urothelial tract tumors. Ann Oncol. 1993; 4:403-7.

7. van de Putte EE, Mertens LS, Meijer RP, van der Heijden MS, Bex A, van der Poel HG, Kerst JM, Bergman AM, Horenblas S, van Rhijn BW. Neoadjuvant induction dose-dense MVAC for muscle invasive bladder cancer: efficacy and safety compared with classic MVAC and gemcitabine/cisplatin. World J Urol. 2016; 34:157-62.

8. Sternberg CN, de Mulder PH, Schornagel JH, Théodore C, Fossa SD, van Oosterom AT, Witjes F, Spina M, van Groeningen CJ, de Balincourt C, Collette L. Randomized phase III trial of high-dose-intensity methotrexate, vinblastine, doxorubicin, and cisplatin (MVAC) chemotherapy and recombinant human granulocyte colony-stimulating factor versus classic MVAC in advanced urothelial tract tumors: European Organization for Research and Treatment of Cancer Protocol no. 30924. J Clin Oncol. 2001; 19:2638-46.

9. Pouessel D, Chevret S, Rolland F, Gravis G, Geoffrois L, Roubaud G, Terrisse S, Boyle H, Chevreau C, Dauba J, Moriceau G, Alexandre I, Deplanque G, et al. Standard or accelerated methotrexate, vinblastine, doxorubicin and cisplatin as neoadjuvant chemotherapy for locally advanced urothelial bladder cancer: Does dose intensity matter. Eur J Cancer. 2016; 54:69-74.

10. Choueiri TK, Jacobus S, Bellmunt J, Qu A, Appleman LJ, Tretter C, Bubley GJ, Stack EC, Signoretti S, Walsh M, Steele G, Hirsch M, Sweeney CJ, et al. Neoadjuvant dosedense methotrexate, vinblastine, doxorubicin, and cisplatin with pegfilgrastim support in muscle-invasive urothelial cancer: pathologic, radiologic, and biomarker correlates. J Clin Oncol. 2014; 32:1889-94.

11. Galsky MD, Iasonos A, Mironov S, Scattergood J, Boyle MG, Bajorin DF. Phase II trial of dose-dense doxorubicin plus gemcitabine followed by paclitaxel plus carboplatin in patients with advanced urothelial carcinoma and impaired renal function. Cancer. 2007; 109:549-55. 
12. Plimack ER, Hoffman-Censits JH, Viterbo R, Trabulsi EJ, Ross EA, Greenberg RE, Chen DY, Lallas CD, Wong YN, Lin J, Kutikov A, Dotan E, Brennan TA, et al. Accelerated methotrexate, vinblastine, doxorubicin, and cisplatin is safe, effective, and efficient neoadjuvant treatment for muscleinvasive bladder cancer: results of a multicenter phase II study with molecular correlates of response and toxicity. J Clin Oncol. 2014; 32:1895-901.

13. Blick C, Hall P, Pwint T, Al-Terkait F, Crew J, Powles T, Macaulay V, Munro N, Douglas D, Kilbey N, Protheroe A, Chester JD. Accelerated methotrexate, vinblastine, doxorubicin, and cisplatin (AMVAC) as neoadjuvant chemotherapy for patients with muscle-invasive transitional cell carcinoma of the bladder. Cancer. 2012; 118:3920-7.

14. McConkey DJ, Choi W, Shen Y, Lee IL, Porten S, Matin SF, Kamat AM, Corn P, Millikan RE, Dinney C, Czerniak B, Siefker-Radtke AO. A Prognostic Gene Expression Signature in the Molecular Classification of Chemotherapynaïve Urothelial Cancer is Predictive of Clinical Outcomes from Neoadjuvant Chemotherapy: A Phase 2 Trial of Dose-dense Methotrexate, Vinblastine, Doxorubicin, and Cisplatin with Bevacizumab in Urothelial Cancer. Eur Urol. 2015; 69:855-62.

15. Edeline J, Loriot Y, Culine S, Massard C, Albiges L, Blesius A, Escudier B, Fizazi K. Accelerated MVAC chemotherapy in patients with advanced bladder cancer previously treated with a platinum-gemcitabine regimen. Eur J Cancer. 2012; 48:1141-6.

16. Sternberg CN, de Mulder P, Schornagel JH, Theodore C, Fossa SD, van Oosterom AT, Witjes JA, Spina M, van Groeningen CJ, Duclos B, Roberts JT, de Balincourt C, Collette L. Seven year update of an EORTC phase III trial of high-dose intensity M-VAC chemotherapy and G-CSF versus classic M-VAC in advanced urothelial tract tumours. Eur J Cancer. 2006; 42:50-4.

17. Bamias A, Dafni U, Karadimou A, Timotheadou E, Aravantinos G, Psyrri A, Xanthakis I, Tsiatas M, Koutoulidis V, Constantinidis C, Hatzimouratidis C, Samantas E, Visvikis A, et al. Prospective, open-label, randomized, phase III study of two dose-dense regimens MVAC versus gemcitabine/cisplatin in patients with inoperable, metastatic or relapsed urothelial cancer: a Hellenic Cooperative Oncology Group study (HE 16/03). Ann Oncol. 2013; 24:1011-7.

18. Petrelli F, Coinu A, Cabiddu M, Ghilardi M, Vavassori I, Barni S. Correlation of pathologic complete response with survival after neoadjuvant chemotherapy in bladder cancer treated with cystectomy: a meta-analysis. Eur Urol. 2014; 65:350-7.

19. Houssami N, Macaskill P, von MG, Marinovich ML, Mamounas E. Meta-analysis of the association of breast cancer subtype and pathologic complete response to neoadjuvant chemotherapy. Eur J Cancer. 2012; 48:3342-54.

20. Maas M, Nelemans PJ, Valentini V, Das P, Rödel C, Kuo LJ, Calvo FA, García-Aguilar J, Glynne-Jones R,
Haustermans K, Mohiuddin M, Pucciarelli S, Small W, et al. Long-term outcome in patients with a pathological complete response after chemoradiation for rectal cancer: a pooled analysis of individual patient data. Lancet Oncol. 2010; 11:835-44.

21. Guiu S, Gauthier M, Coudert B, Bonnetain F, Favier L, Ladoire S, Tixier H, Guiu B, Penault-Llorca F, Ettore F, Fumoleau P, Arnould L. Pathological complete response and survival according to the level of HER-2 amplification after trastuzumab-based neoadjuvant therapy for breast cancer. Br J Cancer. 2010; 103:1335-42.

22. Hurley J, Doliny P, Reis I, Silva O, Gomez-Fernandez C, Velez P, Pauletti G, Powell JE, Pegram MD, Slamon DJ. Docetaxel, cisplatin, and trastuzumab as primary systemic therapy for human epidermal growth factor receptor 2positive locally advanced breast cancer. J Clin Oncol. 2006; 24:1831-8.

23. Sonpavde G, Sternberg CN. Treatment of metastatic urothelial cancer: opportunities for drug discovery and development. BJU Int. 2008; 102:1354-60.

24. Apolo AB, Kim JW, Bochner BH, Steinberg SM, Bajorin DF, Kelly WK, Agarwal PK, Koppie TM, Kaag MG, Quinn DI, Vogelzang NJ, Sridhar SS. Examining the management of muscle-invasive bladder cancer by medical oncologists in the United States. Urol Oncol. 2014; 32:637-44.

25. Wang-Lopez Q, Chalabi N, Abrial C, Radosevic-Robin N, Durando X, Mouret-Reynier MA, Benmammar KE, Kullab S, Bahadoor M, Chollet P, Penault-Llorca F, Nabholtz JM. Can pathologic complete response (pCR) be used as a surrogate marker of survival after neoadjuvant therapy for breast cancer. Crit Rev Oncol Hematol. 2015; 95:88-104.

26. Rustin GJ, Quinn M, Thigpen T, du BA, Pujade-Lauraine E, Jakobsen A, Eisenhauer E, Sagae S, Greven K, Vergote I, Cervantes A, Vermorken J. Re: New guidelines to evaluate the response to treatment in solid tumors (ovarian cancer). J Natl Cancer Inst. 2004; 96:487-8.

27. Adamo B, Deal AM, Burrows E, Geradts J, Hamilton E, Blackwell KL, Livasy C, Fritchie K, Prat A, Harrell JC, Ewend MG, Carey LA, Miller CR, et al. Phosphatidylinositol 3-kinase pathway activation in breast cancer brain metastases. Breast Cancer Res. 2011; 13:R125.

28. Wiggans AJ, Cass GK, Bryant A, Lawrie TA, Morrison J. Poly(ADP-ribose) polymerase (PARP) inhibitors for the treatment of ovarian cancer. Cochrane Database Syst Rev. 2015; 5: CD007929.

29. Jadad AR, Moore RA, Carroll D, Jenkinson C, Reynolds DJ, Gavaghan DJ, McQuay HJ. Assessing the quality of reports of randomized clinical trials: is blinding necessary. Control Clin Trials. 1996; 17:1-12.

30. AlHajri L, Jabbari S, AlEmad H, AlMahri K, AlMahri M, AlKitbi N. The Efficacy and Safety of Edoxaban for VTE Prophylaxis Post-Orthopedic Surgery: A Systematic Review. J Cardiovasc Pharmacol Ther. 2016; 22:230-238. 